\title{
Measurement of body fluid proteins by polyacrylamide gel electrophoresis
}

\author{
MH JOHNSON, EJ THOMPSON \\ From the Department of Chemical Pathology, Institute of Neurology, Queen Square, London WC1N3BG
}

SUMMARY A development of the disc polyacrylamide gel electrophoretic system of Ornstein and Davis, which has been applied to the analysis of unconcentrated cerebrospinal fluid, is described. Modifications to the scanning densitometer have improved the signal:noise ratio of the gel scanning system. Using this technique, we have studied the dye-binding properties of albumin, and of beta- and gamma-globulins, and have shown that reproducible quantification of proteins can be achieved. The advantages of electrophoretic methods over immunochemical methods of quantification are discussed.

Accurate quantification of proteins in body fluids is of fundamental importance to the study of their functions and behaviour in disease. Three approaches have been used to measure the concentration of individual proteins in the presence of other proteins. The first is a chemical approach which can be used if the individual protein has some unique property which allows it to be measured without interference from other proteins. For example, caeruloplasmin acts as an oxidative enzyme and its concentration can be estimated by measuring the product generated when a suitable substrate is added to the unknown serum. ${ }^{1}$ Unfortunately, few proteins have properties suitable for this strategy to be applied. The second, and most widely applied strategy is immunological. The individual protein is purified, and used to immunise an animal whose serum is then titrated against the fluid containing an unknown quantity of the protein. Quantification is achieved by four methods, (i) radial immunodiffusion, (ii) electroimmunoassay, (iii) nephelometry and (iv) radioimmunoassay. The third approach depends upon the physical differences of size, configuration and charge between different proteins. The individual protein is separated by a process such as electrophoresis, and measured by the binding of a stain or antibody, linked to an indicator such as a radioactive label or an enzyme. Some electrophoretic media have a sieving action so that proteins may be separated on the basis of size or configuration as well as charge, and such methods will allow fragments or complexes to be separately detected from their parent molecules as a result of difference in their mobilities.

Much work on cerebrospinal fluid (CSF) proteins has depended on immunological quantification methods, but these methods are only reliable if there is identical antigenic structure between the protein used to immunise

Accepted for publication 12 May 1982 the animal, the protein used as a standard and the protein being estimated. Up to $200 \%$ overestimation of CSF IgG has been reported ${ }^{2}$ with such methods, particularly with monoclonal and presumably oligoclonal IgG. Secondly, the antibodies used must be directed only against the protein being measured, and not cross-react with other proteins. In CSF, it is known that certain proteins exist in a form different to that found in the blood. For example? prealbumin may form a complex with a retinol-binding protein and is not identical immunologically in the two fluids. ${ }^{34}$ Also a derivative of transferrin called Tau protein is relatively abundant in CSF but is not usually found in serum. Antitransferrin antibodies cross-react with Tau protein and would therefore measure it as transferrin. Other proteins for which comparisons between CSF and serum have been found to be unreliable are haptoglobin and $\beta_{1 \mathrm{C}} / \boldsymbol{\beta}_{1 \mathrm{~A}}$ globulin. ${ }^{5}$ Electrophoresis demonstrates physical differences between the same protein in CSF and serum because the electrophoretic mobility is altered. It should, therefore, be more reliable for comparisons of proteins on either side of the blood-CSF barrier. For these reasons, we have attempted to evaluate the electrophoretic approach to the measurement of proteins in serum, CSF and other body fluids such as aqueous humour. These methods are generally thought to be only semiquantitative, but by directing meticulous attention to the electrophoretic methods in use in this Institute for the last 19 years, we have been able to show that precision can be improved so that reliable quantitative results can be obtained from a small volume of CSF, using polyacrylamide gel electrophoresis.

\section{Material and methods}

The electrophoretic system used was essentially the small pore disc polyacrylamide gel system of Ornstein and Davis, ${ }^{6}$ which was available as a preprint from Eastman 
Kodak Company in 1962. There was no sample gel, nor stacking gel and sucrose was not added to the sample. The separation gel was $7 \%(\mathrm{wt} / \mathrm{vol}$ ) acrylamide, $2 \cdot 6 \%$ (as a percentage of monomer) bis-acrylamide (Serva), in a 0.76 $M$ Tris-Cl buffer ( $\mathrm{pH} \mathrm{8.9),} \mathrm{containing} 0.07 \%$ (wt/vol) ammonium persulphate and $0.029 \%(\mathrm{vol} / \mathrm{vol})$ TEMED as catalyst-accelerator agents. This solution was pipetted into Pyrex glass tubing, $5 \mathrm{~mm}$ internal diameter, $20 \mathrm{~cm}$ long, which had been previously coated with Photo-flo 600 (Eastman). After polymerisation, Hyland Q-Pak, CSF control was made up as directed, and then known amounts (by weight), suitably diluted in $0.15 \mathrm{M} \mathrm{NaCl}$, were applied to the tops of the gels. Five mmol Tris-38 mmol glycine buffer $\mathrm{pH} 8.3$ containing 2 or 3 drops of $0.01 \%(\mathrm{wt} / \mathrm{vol}$ ) bromophenol blue (Sigma), was pipetted above the sample layer and placed in tanks connected by the gel tubes. A current of up to $2.5 \mathrm{~mA}$ per gel was applied through platinum electrodes with the sample proteins running towards the anode until the marker dye reached the bottom of the gel tubes (about three hours). The gels were then removed and stained in Coomassie Brilliant Blue $\mathrm{G} 250$ solution at $60^{\circ} \mathrm{C}$ for $2 \mathrm{~h}$ or in naphthalene black solution at room temperature for $1 \mathrm{~h}$. The former was made by dissolving $100 \mathrm{mg}$ Coomassie Brilliant Blue G250 (Sigma) in about $200 \mathrm{ml}$ water. To this solution, $7.5 \mathrm{ml} 70 \%$ (vol/vol) perchloric acid was slowly added with vigorous mechanical stirring. The volume of the solution was then brought to $250 \mathrm{ml}$ with water, stirred for one hour and filtered. ${ }^{7}$ Alternatively, gels were stained in a solution of one gram naphthalene black (Hopkins and Williams, Ltd) dissolved in $100 \mathrm{ml}$ $7 \%$ (vol/vol) acetic acid. Whichever stain was used, the gels were destained in several changes of $7 \%$ acetic acid until the background was clear, and could then be stored in this solution.

\section{SCANNING}

We have made various modifications to the Joyce Loebl Chromoscan 200 in order to improve the signal:noise ratio of the system. In the usual configuration, the gel is placed in a cylindrical tube which refracts the light beam, of which only about one third reaches the photomultiplier tube. In the conventional position, the turns of the coil in the photomultiplier tube are parallel to the slit through which the light beam passes (Fig. 1). In these experiments, we scanned the gels in a specially constructed cuvette with rectangular sides which was filled with 7\% acetic acid so that there was no change in refractive index as the light beam passed across the surfaces of the gel. We also rotated the photomultiplier tube through $90^{\circ}$ (Fig. 2), and moved it closer to the gel so that all the light beam was impinging on the photomultiplier coil. With this arrangement, we tested the resolution of the scanner using a grid supplied by the manufacturers of a laser beam recording densitometer. This showed our system to be capable of resolving bands separated by $65 \mu \mathrm{m}$ with the same

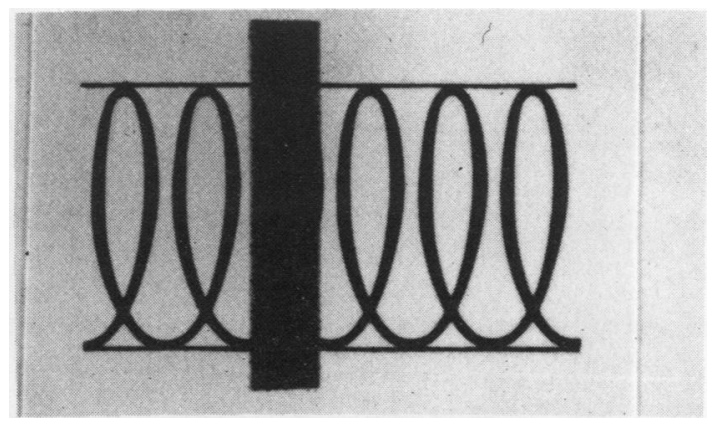

Fig. 1 Diagram to show collimated light beam at $90^{\circ}$ to the turns of the photomultiplier.

discrimination as the laser, (Fig. 3). Gels were scanned using light passed through two Kodak Wratten filters (Nos 9 and 15).

\section{QUANTIFICATION}

To assess the reproducibility of the method we measured the peak heights and areas of the albumin, transferrin and gamma-globulin regions of the densitometer trace of the gel. Areas were measured by a planimeter or a computer-aided bit pad (MOP-AMO ${ }_{3}$ by KontronMessgerate $\mathrm{GmbH}$ ). To allow for any variations in staining or in amount of protein added, we conventionally express peak heights or areas as ratios to the peak height or area of transferrin.

\section{STATISTICS}

Means and standard deviations were calculated from the peak height and area measurements and the coefficient of variation was derived by dividing the standard deviation by the mean and multiplying by 100 . For the dye binding experiments, a linear regression programme was used to fit the points to a straight line and to calculate the slope

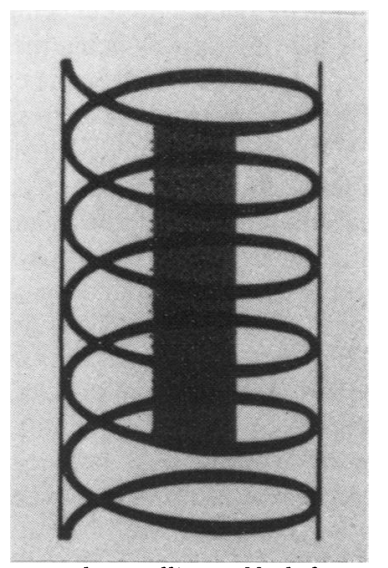

Fig. 2 Diagram to show collimated light beam rotated through $90^{\circ}$ so as to fall across the turns of the photomultiplier coil . 


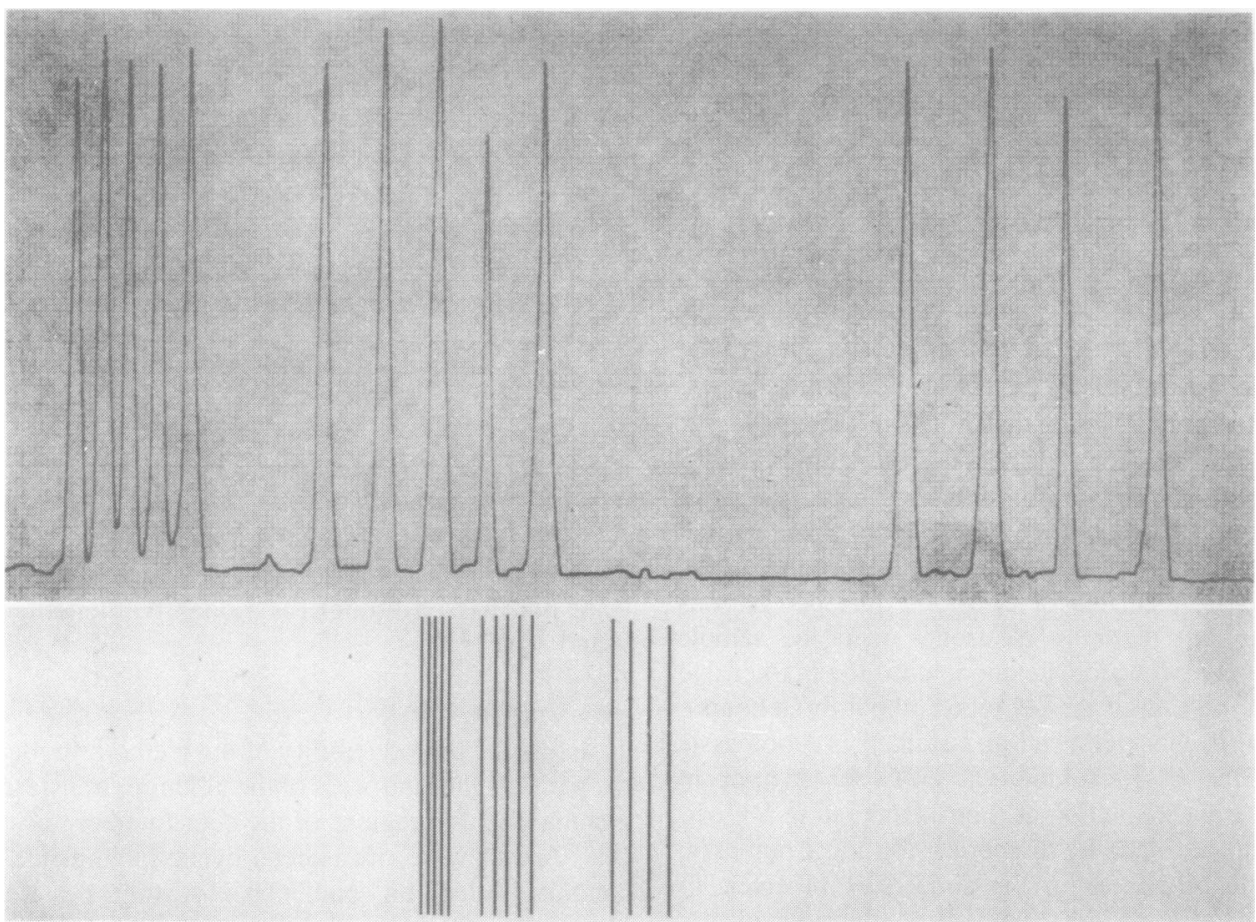

Fig. 3 Photograph showing (below) an enlargement of a test grid made up of groups of lines separated by $65 \mu \mathrm{m}$, $160 \mu \mathrm{m}$ and $320 \mu \mathrm{m}$, and (above) the scan produced by the modified Joyce Loebl densitometer of this test grid.

and $y$ intercept for each equation of linear regression. The correlation coefficient is given as $r$.

\section{Result:}

Figure 4 shows the correlation between the amount of protein added to the gel and the size of the appropriate area on the densitometer scan after the gel had been stained with Coomassie. Figure 5 shows the same correlation when naphthalene black was used to stain the gels. Note that the weight of the individual protein being measured is not given because the protein was being measured in the presence of other proteins, as would be the case with CSF or serum. However, the figures given correspond roughly to micrograms of total protein added as measured by nephelometry after $40 \%$ polyethylene glycol precipitation. The dotted lines represent the quantity of total protein routinely added to gels for electrophoresis $(100 \mu \mathrm{g}$ for Coomassie and $200 \mu \mathrm{g}$ for naphthalene black). Table 1 gives the slopes of the regression lines for binding of Coomassie and naphthalene black to albumin, transferrin and gammaglobulin, and the ratio of the Coomassie slope to the naphthalene black slope for albumin, transferrin and gammaglobulin. It can be seen that the system is two to three times more sensitive using Coomassie than using naphthalene black. Table 2 gives the ratios in which Coomassie and naphthalene black bind to the three types of protein, giving albumin an arbitrary value of 100 units

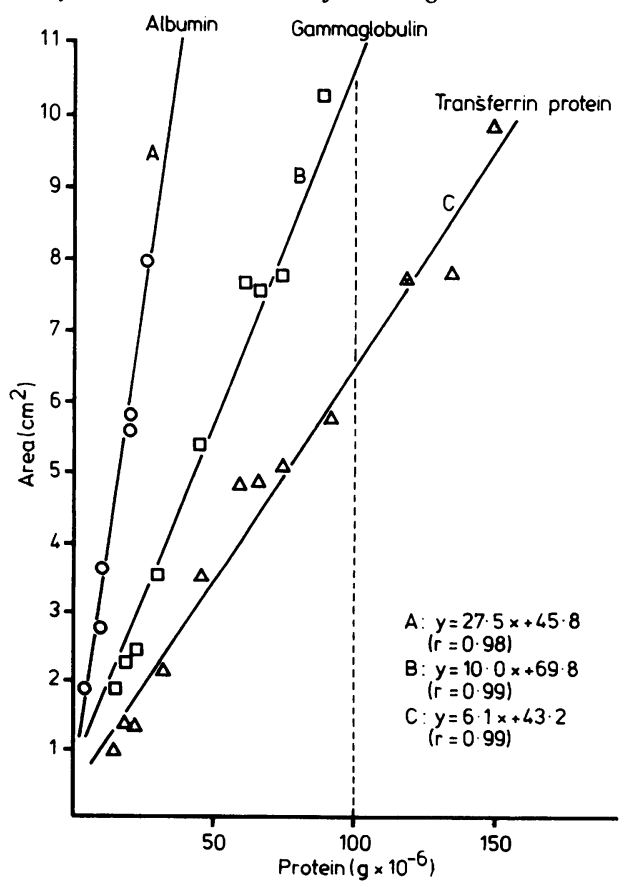

Fig. 4 Correlation between Q-Pak control CSF run on a gel and area of each peak on the densitometer scan when Coomassie stain is used. The dotted line indicates the usual amount of protein added. 


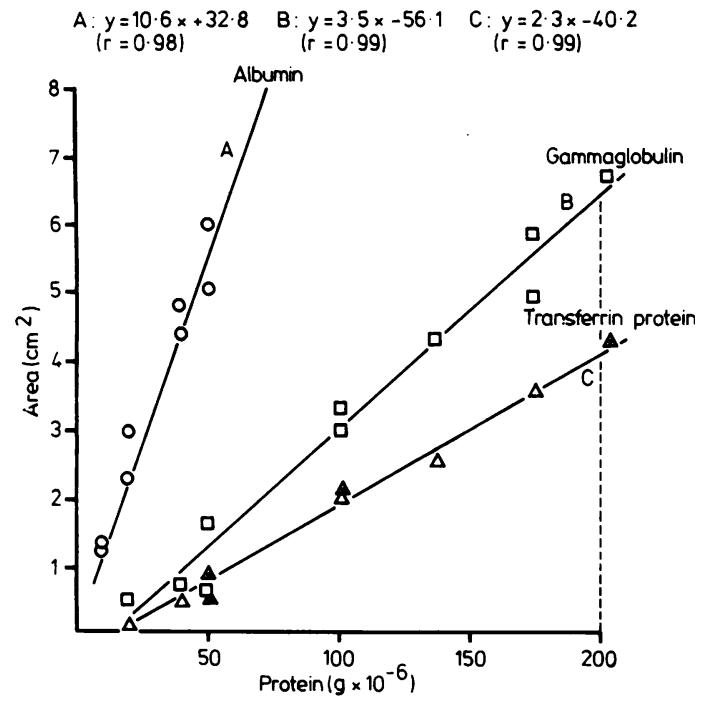

Fig. 5 Correlation between Q-Pak control CSF run on a gel and area of each peak on the densitometer scan when naphthalene black stain is used. The dotted line indicates the usual amount of protein added.

of area in each case. In a second series of experiments, quantities of Hyland Q-Pak control CSF comparable to the quantities of CSF and serum usually applied were run on different days (between batch run) and on the same day (within batch run). To assess the degree of error
Table 1 Slopes of regression lines for binding of Coomassie (Fig. 4) and naphthalene black (Fig. 5) to albumin, transferrin and gammaglobulin, and the derived ratios of the Coomassie slope to the naphthalene black slope

\begin{tabular}{llll}
\hline & Albumin & Transferrin & Gammaglobulin \\
\hline $\begin{array}{l}\text { Slope of Coomassie } \\
\text { regression line }\end{array}$ & 27.5 & 6.1 & 10.0 \\
$\begin{array}{l}\text { Slope of naphthalene } \\
\text { black regression line }\end{array}$ & 10.6 & 2.3 & 3.5 \\
\begin{tabular}{l} 
Ratio: Coomassie slope \\
\cline { 2 - 4 } Naphthalene black slope
\end{tabular} & 2.6 & 2.7 & 2.9 \\
\hline
\end{tabular}

Table 2 Relative binding of Coomassie and naphthalene black to albumin, transferrin and gammaglobulin. The albumin peak has been assigned an arbitrary area of 100 units

\begin{tabular}{llll}
\hline & Albumin & Transferrin & Gammaglobulin \\
\hline $\begin{array}{l}\text { Relative binding of } \\
\begin{array}{c}\text { Coomassie } \\
\text { Relative binding of } \\
\text { naphthalene black }\end{array}\end{array}$ & 100 & $22 \cdot 1$ & $36 \cdot 3$ \\
\hline
\end{tabular}

introduced at the scanning stage, the same gel was scanned on different days (between batch scans) and on the same day (within batch scans). Finally, the same gel was scanned ten times without removing it from the scanner (intrinsic scanner variation). The results of these precision experiments are set out in Table 3, which shows the coefficient of variation for the peak heights and areas of transferrin and gammaglobulin as well as the coeffi-

Table 3 Coefficients of variation (CV) of the peak heights and areas for transferrin and gammaglobulin, and for the ratios of gammaglobulin to transferrin

\begin{tabular}{|c|c|c|c|c|c|c|c|}
\hline & \multirow[t]{2}{*}{ No } & \multicolumn{2}{|l|}{ Transferrin } & \multicolumn{2}{|c|}{ Gammaglobulin } & \multicolumn{2}{|c|}{$\frac{\text { Gammaglobulin }}{\text { Transferrin }}$} \\
\hline & & $\begin{array}{l}\text { CV of } \\
\text { peak height } \\
\text { (\%) }\end{array}$ & $\begin{array}{l}\text { CV of } \\
\text { area } \\
\text { (\%) }\end{array}$ & $\begin{array}{l}\text { CVof } \\
\text { peak height } \\
\text { (\%) }\end{array}$ & $\begin{array}{l}\text { CV of } \\
\text { area } \\
\text { (\%) }\end{array}$ & $\begin{array}{l}\text { CV of ratios } \\
\text { of peak heights } \\
\text { (\%) }\end{array}$ & $\begin{array}{l}\text { CV of ratios } \\
\text { of areas } \\
\text { (\%) }\end{array}$ \\
\hline Intrinsic scanner variation & 10 & 0.9 & $2 \cdot 3$ & 0.9 & $1 \cdot 3$ & 0.7 & $2 \cdot 1$ \\
\hline Within batch scanner variation & 10 & $2 \cdot 6$ & $3 \cdot 1$ & $2 \cdot 9$ & $3 \cdot 1$ & $2 \cdot 0$ & 1.8 \\
\hline Between batch scanner variation & 10 & $6 \cdot 3$ & $5 \cdot 4$ & $5 \cdot 3$ & $6 \cdot 4$ & $2 \cdot 6$ & $2 \cdot 7$ \\
\hline Within batch run variation & 10 & $9 \cdot 2$ & $7 \cdot 6$ & $8 \cdot 0$ & $9 \cdot 7$ & $3 \cdot 4$ & 6.6 \\
\hline Between batch run variation & 10 & $8 \cdot 4$ & $4 \cdot 2$ & $12 \cdot 3$ & $6 \cdot 1$ & $9 \cdot 5$ & $3 \cdot 0$ \\
\hline
\end{tabular}

Table 4 Coefficients of variation for various methods used to quantify proteins in cerebrospinal fluid

\begin{tabular}{|c|c|c|c|c|}
\hline \multirow[t]{2}{*}{ Method } & \multirow[t]{2}{*}{ Comparison } & \multicolumn{2}{|c|}{ Coefficient of variation } & \multirow[t]{2}{*}{ Reference } \\
\hline & & $\begin{array}{l}\text { Transferrin } \\
\text { (\%) }\end{array}$ & $\begin{array}{l}\text { Gammaglobulin } \\
\text { (\%) }\end{array}$ & \\
\hline Radial immunodiffusion & - & 11 & $8-9$ & 8 \\
\hline Elect! oimmunoassay & between batch & $4-8$ & & 5 \\
\hline Laser nephelometry & between batch & $7-11$ & 4-9 & 9 \\
\hline Nephelometry (centrifugal analyser) & between batch & & $4-5$ & 10 \\
\hline Nephelometry (centrifugal analyser) & within batch & & $3-4$ & 10 \\
\hline Electrophoresis (celluiose acetate) & within batch & $2 \cdot 9$ & $8 \cdot 5$ & 11 \\
\hline Electrophoresis (polyacrylamide) & within batch & $5 \cdot 9$ & & 12 \\
\hline Electrophoresis (polyacrylamide) & between batch & $4 \cdot 2$ & $6 \cdot 1$ & This study \\
\hline
\end{tabular}


cient of variation for the ratios of the peak heights and areas of gammaglobulin to transferrin. Table 4 shows a comparison of these results with those of other methods used to quantify proteins in CSF.

\section{Discussion}

Since the description by Ornstein and Davis ${ }^{6}$ in 1962 of electrophoresis in cylindrical polyacrylamide gels, we have developed a variety of modifications to improve the application of the method to routine analysis of CSF proteins. The method here described does not require a stacking gel or sucrose, and has been shown to identify a variety of important abnormalities in unconcentrated CSF. ${ }^{13}$ The loss of small proteins such as prealbumin and cathodic proteins such as locally-produced gammaglobulins has been observed with concentration methods, ${ }^{1114}$ and is avoided with this method.

\section{ACCURACY AND SPECIFICITY}

The results show that Coomassie is a more sensitive dye for proteins than is naphthalene black, and that the difference between these stains is more marked for gammaglobulins than for albumin. For quantitative purposes, the results show that binding of the stains is linear over the range of protein concentrations at which electrophoresis is routinely performed, except in the case of albumin, which is always in saturation. However, the binding affinity for one protein will differ from that for another protein so that quantitative comparisons of one protein with another protein may not be reliable.

In the second part of this study, quality control experiments have shown the variation introduced at various stages of the procedure. We have demonstrated that carefully performed electrophoretic runs can give results with acceptable reproducibility, comparable with other commonly used methods.

\section{Conclusions}

The main advantage of electrophoretic methods of quantification is that alterations in the physical state of the protein being studied cause a change in its electrophoretic mobility. Fragments such as Tau protein and complexes such as haemoglobin-haptoglobin complexes run separately from the native protein. This distinction is particularly relevant when comparisons are being made between quantities of proteins in two different fluids such as blood and CSF; CSF is formed by mechanisms which may favour the passage of small molecules, so that monomeric forms, for example, of IgM, may be relatively enriched and polymeric forms relatively excluded. ${ }^{4}$ Immunochemical methods cannot distinguish different physical forms of the same protein and are potentially unreliable when comparing CSF with serum. It is now possible to demonstrate the positions of 10 or more proteins that form a discrete peak or area on the pherogram, ${ }^{15}$ and provided the mobility of the peaks is identical in CSF and serum, it is safe to assume that quantity of protein can be compared. If a suitable purified preparation of the protein is available, a standard curve can be drawn and the protein quantified in absolute amounts, but more usually, quantities are expressed as a ratio of the protein to a well recognised peak such as transferrin, which shows little biological variation in CSF, or prealbumin, which has a linear relation to the total protein of the CSF. The differences in avidity of binding of dyes to proteins means that one protein cannot reliably be compared with a different protein, but variable binding of different dyes can be useful in practice because the basic oligoclonal immunoglobulin bands seen in CSF in conditions such as multiple sclerosis are more easily seen in the Coomassiestained gel, whereas acidic proteins in the same region of the gel, such as haptoglobins, are equally prominent on gels stained with Coomassie or naphthalene black.

The limitation of electrophoretic methods is that not all proteins can be separated to form measurable peaks. Also, IgG molecules form a diffusely stained region rather than a band, and some fragments, for example, light chains, and some complexes, for example, antigen-antibody complexes, run in the gamma region. However, Takeoka et $a^{16}{ }^{16}$ showed that most light chain fragments ran in the $\beta_{2}$ zone on polyacrylamide, and Maidment et al $^{17}$ found that albumin:antialbumin complexes did not enter polyacrylamide gel so that the method does, to some degree, reduce errors from these effects. The most reliable results are likely to come from comparisons between physical methods such as chromatographic and electrophoretic methods and immunochemical methods, with careful studies of discrepancies when they occur.

This work was supported in part by a grant from the Medical Research Council.

\section{References}

' Sunderman FW, Nomoto S. Measurement of human serum ceruloplasmin by its $p$-phenylenediamine oxidase activity. Clin Chem 1970;16:903-10.

2 Grubb A. Immunochemical quantitation of IgG: influences of the antiserum and of the antigenic population. Scand J Clin Lab Invest 1973;31:465-72.

${ }^{3}$ Laurell C-B. Electroimmunoassay. Scand J Clin Lab Invest 1972;29, suppl 124:21-37.

${ }^{4}$ Felgenhauer K. Protein size and cerebrospinal fluid composition. Klin Wochenschr 1974;52:1158-64.

${ }^{5}$ Bock E. Quantitation of plasma proteins in cerebrospinal fluid. Scand J Immunol 1973;2, suppl 1:111-7.

6 Davis BJ. Disc electrophoresis-II. Method and application to human serum proteins. Ann N Y Acad Sci 1964;121:404-27.

7 Vesterberg O, Hansén L, Sjösten A. Staining of proteins after isoelectric focusing in gels by new procedures. Biochim Biophys Acta 1977;491:160-6.

${ }^{8}$ Schulman G. Comparison of specific protein assays in biological fluid by radial immunodiffusion and laser nephelometry. Clin Biochem 1979;12:123-5. 
${ }^{9}$ Schulman G. Quality of commercially available controls in laser immunonephelometry. Ann Clin Biochem 1980;17:178-82.

${ }^{10}$ Jefferis R, Deverill I, Ling NR, Reeves WG. Quantitation of human total IgG, kappa IgG and lambda IgG in serum using monoclonal antibodies. J Immunol Methods 1980;39:355-62.

" Kleine TO, Ströh J. Neue Mikroelektrophorese für nativen Lumballiquor. Unterschiede im Pherogramm von nativen und konzentrierten Proteinen. J Clin Chem Clin Biochem 1974;12:73-80.

${ }^{12}$ Abraham K, Schütt K, Müller I. Hoffmeister H. Kontinuierliche Polyacrylamid-elektrophorese. 1. Untersuchungen an Normalseren. J Clin Chem Clin Biochem 1970;8:92-8.

${ }^{13}$ Johnson M, Thompson EJ. Proteins of the cerebrospinal fluid. Hospital Update 1981;7:1155-63.

${ }^{14}$ Mattson DH, Roos RP, Arnason BGW. Immunoperoxidase staining of cerebrospinal fluid IgG in isoelectric focusing gels. A sensitive new technique. J Neurosci Methods 1980;3:67-75.
${ }^{15}$ Johnson MH, Walker RWH, Keir G. Thompson EJ. A new method for identification of proteins separated in polyacrylamide gels. Biochem Soc Trans 1982;10:32-3.

16 Takeoka T, Gotoh F, Furumi K, Mori K. Polyacrylamide-gel disc electrophoresis of native cerebrospinal fluid proteins with special reference to immunoglobulins and some clinical applications. $J$ Neurol Sci 1976;29:213-9.

${ }^{17}$ Maidment BW, Papsidero LD, Chu TM. Isoelectric focusing - a new approach to the study of immune complexes. $J$ Immunol Methods 1980;35:297-306.

Requests for reprints to: Dr EJ Thompson, Department of Chemical Pathology, Institute of Neurology, Queen. Square, London WC1N 3BG, England. 